\title{
INFLUÊNCIA DO MANEJO PRÉ-ABATE DE BOVINOS NA INDÚSTRIA SOBRE OS PARÂMETROS DE BEM-ESTAR ANIMAL E IMPACTOS NO pH 24 HORAS POST MORTEM
}

\author{
INFLUENCE OF HANDLING PRE-SLAUGHTER CATTLE INDUSTRY ON THE \\ PARAMETERS OF ANIMAL WELFARE AND IMPACTS ON $\mathrm{pH} 24$ HOURS POST \\ MORTEM
}

\author{
Claudesina Rodrigues LEITE ${ }^{1}$; Mara Regina Bueno de Mattos NASCIMENTO ${ }^{2}$; \\ Daniela de Oliveira SANTANA ${ }^{3}$; Ednaldo Carvalho GUIMARÃES ${ }^{4}$; Hugo Ribeiro MORAIS ${ }^{1}$ \\ 1. Mestre em Ciências Veterinárias pela Universidade Federal de Uberlândia - UFU, Uberlândia, Minas Gerais, Brasil, \\ claudesinarodrigues@ uol.com.br; 2. Professora Associada, Doutora, Faculdade de Medicina Veterinária - FAMEV - UFU, Uberlândia, \\ MG, Brasil; 3. Médica Veterinária pela UFU, Uberlândia, Minas Gerais, Brasil; 4. Professor Associado, Doutor, Faculdade de \\ Matemática - FAMAT - UFU, Uberlândia, MG, Brasil.
}

\begin{abstract}
RESUMO: Avaliou-se o manejo pré-abate de 320 fêmeas bovinas, divididas em oito lotes de 40 animais, de acordo com a procedência, hígidas e azebuadas com idade entre 2 a 4 anos, provenientes de oito propriedades do Triângulo Mineiro-MG, as quais foram abatidas em um matadouro frigorífico localizado nessa mesma região. Relacionaram-se nesse manejo, parâmetros de bem-estar animal e seus efeitos no atordoamento, sangria e pH 24 horas. Analisou-se a condução dos animais no matadouro frigorífico, desde os currais até o boxe de atordoamento, insensibilização dos bovinos e monitoramento do tempo até a sangria, a eficiência do atordoamento e a mensuração do $\mathrm{pH}$ das carcaças após 24 horas do abate. Ao considerar cada lote de 40 animais, os escorregões e as quedas variaram de $0(0 \%)$ a $2(5 \%)$, e vocalizações de 0 $(0 \%)$ a $10(25 \%)$, contabilizadas durante a condução dos bovinos. O menor valor do uso do bastão elétrico por lote de 40 animais foi de $23(57,5 \%)$ e o maior de $40(100 \%)$, o que reflete a falta de um manejo adequado nesta fase. Os bovinos avaliados após o atordoamento e adequadamente insensibilizados estiveram entre 31 a 40 animais $(77,5 \%$ a $100 \%)$ por lote. A insensibilização com um disparo oscilou de 29 a 36 animais (72,5\% a 90\%), com exceção de um lote, cujo atordoamento não foi eficiente por defeito no equipamento no dia de avaliação e todos os animais receberam mais de um disparo. $\mathrm{O}$ intervalo entre o atordoamento e a sangria não variou $(\mathrm{P}>0,05)$, mantendo-se dentro de um minuto. $\mathrm{O}$ tempo de sangria variou entre lotes $(\mathrm{P}<0,05)$, porém dentro do tempo mínimo preconizado ( 3 minutos), exceto um lote que obteve menor tempo (2,54 minutos). Os valores médios de $\mathrm{pH} 24$ horas post mortem em um lote ficou dentro do ideal que é de até 5,8; seis lotes ficaram entre 5,81 a 5,99, considerados intermediários em relação ao $\mathrm{pH}$ ideal. Em um lote, os valores médios para as carcaças dos bovinos estiveram acima de 6,0; avaliada como parâmetro indesejável. O manejo pré-abate no matadouro frigorífico influencia nos parâmetros de bem-estar animal, pois irregularidade de manutenção de equipamentos e instalações, mão de obra não qualificada e supervisão ineficiente provocam falhas nos processos de atordoamento, sangria e $\mathrm{pH} 24$ horas, com perda da qualidade da carne.
\end{abstract}

PALAVRAS-CHAVE: Abate. Carcaças bovinas. Insensibilização. pH. Qualidade da carne.

\section{INTRODUÇÃO}

Nos últimos 20 anos, principalmente nos países industrializados, os consumidores estão mais preocupados com o bem-estar animal, a qualidade e a segurança dos alimentos (MITCHELL, 2006). De acordo com a Comissão Europeia (2007), 89\% dos consumidores afirmam que os alimentos importados deveriam ser produzidos nas condições de bem-estar animal assim como aqueles produzidos na União Europeia.

O Brasil é o maior exportador mundial de carne bovina (ABIEC, 2012). Portanto, é importante a adaptação de boas práticas de manejo e cuidados favoráveis aos animais de produção, atendendo as exigências dos consumidores, para que o país possa manter essa posição perante o mercado de exportação. Os matadouros frigoríficos exportadores do Brasil devem seguir as normas dos clientes, tal como a União Europeia, que continuamente estabelecem novas regras e leis para o bem-estar dos animais. No Brasil, a legislação de bem-estar animal teve início com o Decreto $\mathrm{n}^{\circ} 24.645 / 1934$, que estabeleceu medidas de proteção animal. A Instrução Normativa de $n^{\circ}$ 03/2000, aprovou o regulamento técnico de métodos de insensibilização para o abate humanitário para animais de açougue. A Portaria $n^{\circ} 185 / 2008$ instituiu a Comissão Técnica Permanente de Bem-estar animal do MAPA, cujo objetivo é coordenar as diversas ações de bem-estar animal e fomentar a adoção das Boas Práticas para o Bem-estar Animal pelos produtores rurais. A Instrução Normativa $n^{\circ} 56 / 2008$ define e recomenda a adoção das boas práticas de bem-estar para animais de produção e de interesse econômico, desde a produção até transporte. O Brasil tende a 
oferecer um desenvolvimento científico para auxiliar na melhora da atividade produtiva da carne, almejando o bem-estar animal e a maior lucratividade do produtor, do empresário industrial e a satisfação do consumidor, beneficiando assim a economia do país. No entanto, conforme Paranhos da Costa (2002), no comércio interno do Brasil não tem sido dada a devida atenção ao bem-estar dos animais para o abate. Os produtores, transportadores e matadouros frigoríficos pouco sabem sobre as consequências do manejo pré-abate inadequado que traz reflexos negativos no ganho dos pecuaristas e das indústrias, como também estresse dos animais.

Paranhos da Costa et al. (2002) mencionam que "Programas de qualidade da carne devem ter como relevância mais do que a oferta de produtos seguros, saudáveis e nutritivos, devem incluir o vínculo com a produção sustentável e a promoção do bem-estar animal e humano, garantindo a renda do produtor e o contentamento do consumidor, sem causar prejuízos ao ambiente".

O bem-estar é definido por um completo estado de saúde física e mental, onde o animal encontra-se em harmonia com seu meio-ambiente (MOLENTO, 2003; BROOM; MOLETO, 2004). Broom e Molento (2004) acrescentam que esta definição deve permitir uma relação com outros conceitos, tais como: necessidades, liberdades, felicidade, adaptação, controle, capacidade de previsão, sentimentos, sofrimento, dor, ansiedade, medo, tédio, estresse e saúde. Molento e Bond (2008) afirmam que uma pecuária mais humanitária eleva os padrões éticos da produção animal. Não obstante o conhecimento científico na área de bemestar animal seja recente, os pontos críticos que restringem a qualidade de vida dos bovinos de produção encontram-se propostos na preocupação da sociedade em relação à qualidade de vida dos animais que são utilizados pelo ser humano, a valorização da qualidade de vida dos animais e dos produtos obtidos dentro de sistemas que visam reduzir o sofrimento animal. A melhoria nas condições de bem-estar dos animais utilizados para produção de alimentos representa uma redução do sofrimento existente.

É importante desenvolver estudos relacionados ao bem-estar animal, o que pode possibilitar melhoria no quadro ético e político do desenvolvimento rural. A mudança nas atitudes das instituições e a conscientização da sociedade a respeito do bem-estar animal no Brasil tem resultado em esforços que melhoram as condições de vida dos animais de produção e de companhia. Independente do formato que as imposições de bemestar animal venham a adquirir no horizonte de comércio entre países, o exportador que ter maior capacidade de atender requisitos de bem-estar animal encontra-se em posição privilegiada nas negociações (MOLENTO, 2003).

Um ótimo ensejo para a melhora nos padrões éticos da produção animal é o reconhecimento e a necessidade de uma pecuária submetida a um manejo e abate mais humanitário (MOLENTO; BOND, 2008). De acordo com estes autores, o produto final dos animais que tiveram bons tratos é de melhor qualidade comparada aos demais.

Os efeitos quantitativos e qualitativos sobre a produção da carne são medidas em geral pelo peso vivo da carcaça, danos nas carcaças (contusões) e alterações de pH e cor da carne (GALLO; TADICH, 2005). Também a determinação do $\mathrm{pH}$ é a forma mais comum e universalmente aceita como indicador da qualidade final da carne e geralmente as medidas são feitas sobre o músculo Longissimus dorsi (PRATA; FUKUDA, 2001),

Um manejo deficiente durante as etapas préabate representa estresse sobre os animais, contusões nas carcaças e alterações químicas, fisiológicas e biológicas da carne, aumentando seu $\mathrm{pH}$, ficando esta mais escura, ocasionando prejuízo para o ser humano e animais.

Objetivou-se neste estudo investigar a influência do manejo pré-abate nos parâmetros de bem-estar animal no atordoamento, sangria e no $\mathrm{pH}$ 24 horas post mortem de bovinos abatidos em um matadouro frigorífico sob inspeção sanitária oficial.

\section{MATERIAL E MÉTODOS}

Foram utilizadas 320 fêmeas, azebuadas, hígidas com idade entre 2 a 4 anos, com peso vivo de 350 a $450 \mathrm{~kg}$, procedentes de oito propriedades rurais localizadas no Triângulo Mineiro-MG, em janeiro, fevereiro, março, julho e agosto de 2009. Estas foram abatidas em um matadouro frigorífico sob inspeção sanitária oficial em Uberlândia-MG. O estudo foi aprovado pela Comissão de Ética e BemEstar Animal - CEUA/UFU (Protocolo $n^{\circ}$ 039/08).

Os animais foram divididos em oito lotes (1, 2, 3, 4, 5, 6, 7 e 8) de 40 animais cada, conforme a procedência, transportados em dois caminhõesboiadeiros, tipo "truck" com capacidade de 20 animais cada, a fim de se avaliar a frequência da utilização de bastões elétricos, ocorrência de escorregões, quedas e vocalização durante a condução dos animais desde os currais de matança até $\mathrm{o}$ boxe de insensibilização, conforme metodologia proposta por Grandin (2005). Estas avaliações foram realizadas no corredor de abate, 
banho de aspersão, seringa e boxe de atordoamento. A eficiência da pistola pneumática no atordoamento e o intervalo de tempo entre insensibilização e sangria também foram medidos de acordo com Grandin (2005).

A frequência de utilização de bastões elétricos foi classificada em: "excelente" quando variava de zero a 5\%; "aceitável" de 6 a 25\%; "não aceitável", de 26 a 49\%; "problema sério", quando apresentava percentual igual ou superior a $50 \%$, conforme Grandin (2005).

Considerou-se queda quando o corpo do animal tocava o piso e escorregões quando existia desequilíbrio do animal, ocorrendo deslocamento involuntário de algum membro (GRANDIN, 2001). $\mathrm{O}$ índice de escorregões e de quedas relacionados a cada lote de 40 animais foi classificado em "excelente", quando não havia quedas e escorregões; "aceitável", quando cada lote apresentava índices menores que 3\% de escorregões e menores que $1 \%$ de quedas; "não aceitável", quando mais de $3 \%$ dos animais escorregaram e quando mais de $1 \%$ tocava o corpo no piso; e "problema sério" quando ocorria mais de 5\% de quedas e $15 \%$ ou mais de escorregões, por lote.

De acordo com Grandin (2001), entende-se por vocalização, qualquer som audível que é emitido pelo animal. As vocalizações dos animais durante a condução no corredor de abate, banho de aspersão, seringa e boxe de atordoamento tem alta correlação com o desconforto e estresse. $\mathrm{O}$ escore para vocalização foi classificado da seguinte forma: "excelente" quando vocalização variava de zero a 0,5\%; "aceitável", quando variava de 0,6 a 3\%; "não aceitável", quando compreendida entre 4 a 10\%; "problema sério", quando superior a $10 \%$ de animais vocalizavam, por lote.

A eficácia do atordoamento foi medida pela porcentagem de animais atordoados com apenas um disparo da pistola pneumática (GRANDIN, 2003). No lote em que 99 a $100 \%$ dos animais recebiam apenas um disparo e já se tornavam insensíveis foi classificado como "excelente"; quando 95 a $98 \%$ dos animais do lote se tornava insensível com apenas um disparo, foi classificado como "aceitável"; quando apenas 90 a 94\% dos animais do lote tornavam insensíveis com apenas um disparo, foi classificado como "não aceitável" e menos de $90 \%$, como "problema sério".

Conforme Grandin (2005), os critérios utilizados para avaliar a sensibilidade dos bovinos após o atordoamento, durante a passagem pela canaleta de sangria foram: presença de vocalização, respiração rítmica, reflexos de correção de postura, movimentos ciliares espontâneos e presença de movimentos ciliares ao toque. Não deve haver movimentos oculares, os olhos devem estar bem abertos com um olhar vazio e o animal nunca deve piscar ou ter reflexo de olho em resposta ao toque. $\mathrm{O}$ animal julgado completamente insensível foi aquele que não apresentou nenhum dos sinais anteriores. Nesta avaliação, considerou-se os 320 bovinos deste estudo (sem avaliação separada em lotes) e o escore utilizado foi: "excelente": inferior a um para 1000 animais; "aceitável": inferior a um para 500 animais que apresente insensibilidade deficiente, portanto, como no presente estudo utilizou-se 320 bovinos estes sinais devem estar ausentes.

O intervalo entre o atordoamento e a sangria admitido foi avaliado, levando-se em consideração o preconizado pelo Regulamento Técnico de métodos de insensibilização para o abate humanitário de animais de açougue (BRASIL, 2000), que estabelece que este período de tempo deve ser de no máximo um minuto. Conforme o Regulamento da Inspeção Industrial e Sanitária de Produtos de Origem Animal (RIISPOA) (1997) e a Padronização de Técnicas, Instalações e Equipamentos de Bovinos (1971) avaliou-se o tempo de sangria cujo tempo mínimo deveria ser de 3 minutos (BRASIL, 1997, 1971). O tempo de sangria foi avaliado desde o momento do corte inicial da barbela, seguido pelo corte dos grandes vasos do pescoço.

A medição do $\mathrm{pH}$ das meias-carcaças foi realizado na profundidade do músculo Longissimus dorsi após 24 horas do abate. Utilizou-se um medidor de $\mathrm{pH}$ portátil, digital (marca Hanna, modelo HI 99163). Para as médias obtidas nas medições considerou-se o valor até 5,80 como $\mathrm{pH}$ ideal, de 5,81 a 5,99 como intermediário e acima de 6,0 como valores indesejáveis e este último valor considerado como a linha divisória entre o corte normal e o escuro, segundo Roça (2000).

Para análise das variáveis tempo de sangria, $\mathrm{pH}$, intervalo entre atordoamento e sangria, utilizouse a análise de variância entre os lotes por meio do programa SISVAR, com o Teste de Tukey nas comparações das médias, a 5\%, segundo Ferreira (2006). Os dados dos parâmetros de bem-estar animal foram avaliados por meio da estatística descritiva.

\section{RESULTADOS E DISCUSSÃO}

Ao analisar cada lote, do curral até a seringa (Tabela 1), os escorregões e as quedas variaram de 0 $(0 \%)$ a $2(5 \%)$, provavelmente como consequência do piso molhado, considerado, portanto critério não aceitável segundo Grandin (2005). Esta autora 
considera não aceitável quando acima de $3 \%$ dos animais escorregam e acima de $1 \%$ toca o corpo no piso. Almeida (2005) ao estudar cinco frigoríficos em São Paulo, no total de 1000 animais estudados, verificou $14,5 \%$ de escorregões e $6,38 \%$ de quedas, durante o trajeto entre o curral de restrição (curral anterior a seringa) e o boxe de atordoamento, especialmente na área de seringa. Segundo Grandin (2005), para evitar escorregões e quedas é relevante o uso de piso antiderrapante nessa área. Piso antiderrapante é essencial para evitar quedas e lesões, sendo difícil o manejo em pisos lisos, pois os animais tornam agitados e perdem o equilíbrio. Todas as áreas por onde o gado anda deve ter uma superfície antiderrapante. O matadouro frigorífico em questão apresentava o piso desgastado e escorregadio.

Tabela 1. Número $(\mathrm{N})$ e porcentagem (\%) de escorregões, quedas, vocalizações e uso de bastão elétrico nos currais, corredor de abate, banho de aspersão e seringa em 320 fêmeas bovinas, divididas em oito lotes de 40 animais, abatidas no matadouro frigorífico com inspeção sanitária oficial, em Uberlândia-MG, 2009.

\begin{tabular}{ccccccccc}
\hline & \multicolumn{2}{c}{ Escorregões } & \multicolumn{2}{c}{ Quedas } & \multicolumn{2}{c}{ Vocalizações } & \multicolumn{2}{c}{ Uso do bastão elétrico } \\
\hline Lotes & $\mathrm{N}$ & $\%$ & $\mathrm{~N}$ & $\%$ & $\mathrm{~N}$ & $\%$ & $\mathrm{~N}$ & $\%$ \\
\hline 1 & 0 & 0 & 0 & 0 & 0 & 0 & 39 & 97,5 \\
2 & 1 & 2,5 & 1 & 2,5 & 2 & 5 & 29 & 72,5 \\
3 & 2 & 5 & 2 & 5 & 5 & 12,5 & 36 & 90 \\
4 & 0 & 0 & 0 & 0 & 1 & 2,5 & 23 & 57,5 \\
5 & 1 & 2,5 & 0 & 0 & 5 & 12,5 & 40 & 100 \\
6 & 0 & 0 & 0 & 0 & 6 & 15 & 38 & 95 \\
7 & 0 & 0 & 0 & 0 & 8 & 20 & 32 & 80 \\
8 & 0 & 0 & 0 & 0 & 10 & 25 & 30 & 75 \\
\hline Total & 4 & 1,25 & 3 & 0,94 & 37 & 11,56 & 267 & 83,44 \\
\hline
\end{tabular}

Neste estudo, a média por lote do escore de vocalização correspondeu a um mínimo de $0(0 \%)$ e máximo de 10 (25\%), então situou no escore superior a $10 \%$ que é considerado como problema sério, conforme Grandin (2005) (Tabela 1). Este resultado pode estar associado principalmente ao uso exagerado do bastão elétrico $(74,2 \%)$, no entanto, outros fatores podem ter contribuído para este problema como escorregões e quedas durante o manejo, bordas afiadas em instalações e pressão excessiva na contenção por parte dos colaboradores. Grandin (1998) ao estudar vocalizações em seis frigoríficos nos Estados Unidos e Canadá, verificou que de 1125 bovinos avaliados 112 vocalizaram $(9,96 \%)$, depois de ter passado por momentos estressantes como choques e escorregões. Esta autora encontrou também uma diminuição de $32 \%$ para $12 \%$ nas vocalizações quando não empregou o uso do bastão elétrico excessivamente. Assim a vocalização detecta problemas de bem-estar que necessitam ser solucionados, tais como uso excessivo de bastão elétrico pelos funcionários, manejo inadequado do gado, distrações e barulhos, os bovinos também tem tendência a se deslocar de um lugar mais escuro para um mais iluminado e em instalações mal iluminadas se recusam a movimentarem, devendo as luzes ficar bem orientadas para os locais que os animais entram.
A faixa de uso do bastão elétrico variou de um mínimo de $23(57,5 \%)$ a um máximo de 40 animais (100\%) por lote (Tabela 1), indicando assim um problema sério, pois indica falhas no correto manejo dos animais e na capacitação dos colaboradores, distração dos animais com barulhos e piso molhado, resultando em esquivamento dos bovinos e consequentemente maior dificuldade de manejo. Resultados semelhantes foram encontrados por Almeida (2005) ao avaliar cinco frigoríficos em São Paulo, observou o uso excessivo do bastão elétrico em todos estabelecimentos sendo, respectivamente, de 84,$54 ; 93,33 ; 90 ; 80$ e $100 \%$. O autor afirma que este resultado pode ter sido reflexo do acúmulo de animais na entrada da seringa e também devido à tentativa de passagem concomitante de dois ou mais animais por alguma abertura, pois estes ficavam "travados", e assim os funcionários exerciam maior pressão na contenção dos bovinos. Grandin (2001) encontrou valores de 95\% do uso do bastão elétrico em animais que paravam durante o manejo quando analisou três plantas de abate. $\mathrm{O}$ aparelho de descarga elétrica deve ser utilizado apenas para mover animais que relutam em caminhar; não deve ser a alternativa primordial para a condução dos animais (GRANDIN, 2009). A autora cita ainda que antes de usar este utensílio deve-se descobrir o motivo da 
Influência do manejo pré-abate...

teimosia desses animais e eliminá-la. A Instrução Normativa $\mathrm{n}^{\mathrm{o}} 3$, de 07 de janeiro de 2000, recomenda que "os dispositivos produtores de descargas elétricas apenas poderão ser utilizados, em caráter excepcional, nos animais que se recusem mover, desde que essas descargas não durem mais do que dois segundos e haja espaço suficiente para que os animais avancem. As descargas elétricas, com voltagens estabelecidas nas normas técnicas que regulam o abate de diferentes espécies, quando utilizadas serão aplicadas somente nos membros". Neste estudo, na condução dos animais utilizou-se sucessivamente o bastão quando os animais se distraíam com barulhos e piso molhado. Às vezes os animais recebiam durante o manejo mais de um toque do bastão elétrico, o que indica uso inadequado e exagerado do bastão elétrico pelos funcionários durante esse período do manejo.

Verificou-se que no boxe de atordoamento os escorregões variaram de $2(5 \%)$ a $10(25 \%)$ por lote e as quedas de $0(0 \%)$ a $2(5 \%)$ (Tabela 2$)$. Esta resposta indica problema sério no manejo realizado pelos funcionários ao conduzir o animal à entrada no boxe de atordoamento o qual apresentava piso escorregadio, e assim, fazia com que o animal ficasse agitado, ocorrendo desequilíbrio e queda, principalmente quando havia uma velocidade maior de abate e os bovinos eram estimulados a
LEITE, C. R. et al.

movimentarem mais rapidamente. Almeida (2005) encontrou valores menores de escorregões (zero) e maiores para quedas $(33,33 \%)$, em dois frigoríficos de São Paulo. O autor relata ainda que os animais entravam numa velocidade maior que a do passo e que quando chegavam dentro do boxe de atordoamento, cujos pisos eram lisos, não conseguiam parar e se desequilibravam e caíam. Conforme Grandin (2005), um bem-estar bom e manejo adequado são impossíveis se os animais escorregam ou caem no piso.

No boxe de atordoamento de os valores mínimos obtidos por lote para vocalização foram de um $(2,5 \%)$ e valores máximos de sete animais $(17,5 \%)$ (Tabela 2), o que resultou também em problema sério, por ser um sinal de desconforto e estresse animal e que possivelmente interfere na insensibilização. Este resultado provavelmente foi devido ao uso de bastão elétrico forçando a entrada dos animais neste local quando estes se recusavam a mover. Gregory et al. (2007) observaram valores inferiores ao deste estudo, de 1608 animais, 1,2\% vocalizaram quando fechados no boxe de atordoamento, relatando a dificuldade dos colaboradores em colocar estes animais no boxe o que levou a uma situação de medo e resposta por meio de vocalizações.

Tabela 2. Ocorrência de escorregões, quedas, vocalizações e eficiência de insensibilização no boxe de atordoamento em 320 fêmeas bovinas, divididos em lotes de 40 animais, abatidas no matadouro frigorífico com inspeção sanitária oficial, em Uberlândia-MG, 2009.

\begin{tabular}{|c|c|c|c|c|c|c|c|c|c|c|}
\hline \multirow[t]{2}{*}{ Lotes } & \multicolumn{2}{|c|}{ Escorregões } & \multicolumn{2}{|c|}{ Quedas } & \multicolumn{2}{|c|}{ Vocalizações } & \multicolumn{2}{|c|}{ Falha no disparo } & \multicolumn{2}{|c|}{$\begin{array}{c}\text { Insensibilizados } \\
\text { com } 1 \text { disparo }\end{array}$} \\
\hline & $\mathrm{N}$ & $\%$ & $\mathrm{~N}$ & $\%$ & $\mathrm{~N}$ & $\%$ & $\mathrm{~N}$ & $\%$ & $\mathrm{~N}$ & $\%$ \\
\hline 1 & 6 & 15 & 0 & 0 & 4 & 10 & 9 & 22,5 & 31 & 77,5 \\
\hline 2 & 2 & 5 & 2 & 5 & 7 & 17 & 11 & 27,5 & 29 & 72,5 \\
\hline 3 & 8 & 20 & 2 & 5 & 1 & 2 & 6 & 15 & 34 & 85 \\
\hline 4 & 8 & 20 & 1 & 2,5 & 2 & 5 & 4 & 10 & 36 & 90 \\
\hline 5 & 8 & 20 & 0 & 0 & 5 & 12,5 & 40 & 100 & 0 & 0 \\
\hline 6 & 6 & 15 & 2 & 5 & 2 & 5 & 8 & 20 & 32 & 80 \\
\hline 7 & 4 & 10 & 0 & 0 & 3 & 7,5 & 4 & 10 & 36 & 90 \\
\hline 8 & 10 & 25 & 0 & 0 & 3 & 7,5 & 7 & 17,5 & 33 & 82,5 \\
\hline Total & 52 & 16,25 & 7 & 2,19 & 27 & 8,44 & 79 & 24,69 & 231 & 72,19 \\
\hline
\end{tabular}

$\mathrm{N}=$ número de animais.

No dia do abate do lote 5 , ocorreu uma falha na pistola pneumática durante o abate, quando falhas no disparo da pistola atingiram percentuais de $100 \%$ dos animais (Tabela 2). Neste dia, o encarregado do setor de manutenção relatou que o compressor de ar estava com defeito, cujo ar não foi enviado em quantidade suficiente para que a pistola pneumática funcionasse corretamente. Nos outros lotes a variação na falha do disparo da pistola foi de
4 a 11 animais (10\% a 27,5\%), por lote de bovinos, especialmente por erro do local de aplicação do disparo. Almeida (2005) encontrou resultados semelhantes ao presente estudo em duas plantas de abate resultando em $12 \%$ e $16 \%$ de falhas. De acordo com este autor, é necessário repetir o disparo sempre que este não é bem executado para que o animal seja devidamente insensibilizado. Andrade et al. (2008) afirmam que é necessário limpeza e 
Influência do manejo pré-abate...

revisões periódicas da pistola e compressor, para ter menor número de disparo por animal, evitando sofrimento, estresse e riscos para o operador.

$\mathrm{O}$ número de bovinos insensibilizados com um disparo variou de $29(72,5 \%)$ a $36(90 \%)$ animais por lote, exceto o lote 5 , em que todos os animais receberam mais de um disparo (Tabela 2). Este resultado pode ter sido causado por falha do equipamento de insensibilização e o operador necessitou realizar outro disparo para que o animal ficasse atordoado. Gallo et al. (2003) alcançaram resultados menores com $72,8 \%$ dos bovinos insensibilizados com um disparo, descrevendo melhoria com a capacitação dos funcionários e equipamentos apropriados. Por outro lado, Neves (2008), no Brasil, encontrou 97,65\% dos animais
LEITE, C. R. et al.

insensibilizados com um disparo, indicando habilidade do funcionário no uso do equipamento.

$\mathrm{Na}$ avaliação dos sinais de insensibilidade dos bovinos após o atordoamento (Tabela 3), verificou-se que de $29(77,5 \%)$ a $40(100 \%)$ dos animais dos diferentes lotes estavam corretamente insensibilizados. $\mathrm{O}$ menor valor, provavelmente foi devido às falhas de equipamento, manejo dos funcionários e supervisão ineficiente por parte de encarregado e gerência. Almeida (2005) avaliando a eficácia da insensibilização em dois frigoríficos brasileiros, obteve como resultado $96 \%$ de insensibilização, valor compatível com os resultados do presente estudo, o autor relatou ainda problemas na contenção dos animais no boxe de atordoamento, aumentando o estresse dos animais.

Tabela 3. Reflexos da insensibilização em 320 fêmeas bovinas, divididas em oito lotes de 40 animais, abatidas no matadouro frigorífico com inspeção sanitária oficial, em Uberlândia-MG, 2009.

\begin{tabular}{ccccccccccccccc}
\hline & \multicolumn{1}{c}{$\mathrm{I}$} & \multicolumn{1}{c}{ MOT } & \multicolumn{1}{c}{ RC } & \multicolumn{2}{c}{ RCP } & \multicolumn{2}{c}{ RR } & \multicolumn{3}{c}{$\mathrm{V}$} & \multicolumn{3}{c}{$\mathrm{S}$} \\
\hline Lotes & $\mathrm{N}$ & $\%$ & $\mathrm{~N}$ & $\%$ & $\mathrm{~N}$ & $\%$ & $\mathrm{~N}$ & $\%$ & $\mathrm{~N}$ & $\%$ & $\mathrm{~N}$ & $\%$ & $\mathrm{~N}$ & $\%$ \\
\hline 1 & 37 & 92,5 & 1 & 2,5 & 0 & 0 & 1 & 2,5 & 1 & 2,5 & 0 & 0 & 3 & 7,5 \\
2 & 37 & 92,5 & 0 & 0 & 1 & 2,5 & 2 & 5 & 0 & 0 & 0 & 0 & 3 & 7,5 \\
3 & 38 & 95,0 & 0 & 0 & 0 & 0 & 2 & 5 & 0 & 0 & 0 & 0 & 2 & 5 \\
4 & 40 & 100 & 0 & 0 & 0 & 0 & 0 & 0 & 0 & 0 & 0 & 0 & 0 & 0 \\
5 & 29 & 72,5 & 0 & 0 & 5 & 12,5 & 4 & 10 & 2 & 5 & 0 & 0 & 11 & 27,5 \\
6 & 38 & 95,0 & 1 & 2,5 & 0 & 0 & 1 & 2,5 & 0 & 0 & 0 & 0 & 2 & 5 \\
7 & 40 & 100 & 0 & 0 & 0 & 0 & 0 & 0 & 0 & 0 & 0 & 0 & 0 & 0 \\
8 & 38 & 95,0 & 0 & 0 & 1 & 2,5 & 1 & 2,5 & 0 & 0 & 0 & 0 & 2 & 5 \\
\hline TOTAL & 297 & 92,80 & 2 & 0,63 & 7 & 2,19 & 11 & 3,44 & 3 & 0,94 & 0 & 0 & 23 & 7,19
\end{tabular}

$\mathrm{N}=$ número de animais, $\mathrm{I}=$ insensibilizados, $\mathrm{MOT}=$ movimentos oculares ao toque, $\mathrm{RC}=$ reflexos ciliares, $\mathrm{RCP}=$ reflexo de correção de postura, $\mathrm{RR}=$ respiração rítmica, $\mathrm{V}=$ vocalização, $\mathrm{S}=$ sensível.

Quanto aos sinais que indicavam que os animais não estavam bem insensibilizados, o reflexo de tentativa de correção de postura foi o mais observado (Tabela 3), com 11 animais dentre os 320 avaliados, variando de um mínimo de $1(2,5 \%)$ a um máximo de $4(10 \%)$, sobretudo no lote 5 que apresentou a maior frequência de animais sensíveis (onze). Este fato pode ser devido aos problemas com equipamento de insensibilização, por falta de manutenção e a ineficiência do manejo desse instrumento pelo funcionário. Gallo et al (2003) observaram num grupo de 335 bovinos, 46,9\% com vocalização após o atordoamento e 66,9\% com reflexo da córnea. Após a instalação de um novo equipamento e a formação de pessoal no reconhecimento dos sinais de sensibilidade, os autores relataram uma melhoria que possibilitou $0 \%$ de vocalização e $0,2 \%$ de reflexo da córnea.

$\mathrm{O}$ número total de animais que estavam sensíveis na ocasião da sangria foi de 23 dentre os 320 avaliados (Tabela 3) e considerou-se como problema sério, pois os animais têm que estar devidamente atordoados e não devem apresentar sinais de sensibilidade, para que seja garantido o abate humanitário e bem-estar animal. De acordo com Grandin (2005), deve-se ter apenas um animal sensível para um lote de 500 animais e se um animal apresentar qualquer sinal de sensibilidade deve ser imediatamente reatordoado antes de qualquer procedimento de abate a ser iniciado.

Não houve variação $(P>0,05)$ entre os lotes quanto ao intervalo de atordoamento e a sangria (Tabela 4). Todos os valores médios observados permaneceram dentro do tempo máximo permitido de um minuto (Brasil, 2000). Resultados discordantes foram obtidos por Gallo et al. (2003) que verificaram que $80,0 \%$ dos animais avaliados apresentavam tempo entre a insensibilização e a sangria entre 1,05 a 4,0 minutos, antes do treinamento dos colaboradores. Após a capacitação dos funcionários houve melhora neste intervalo que passou a ser de menos de 1 minuto em praticamente 
$100 \%$ dos animais. Os autores destacam que a sangria deve realizar-se o mais rapidamente possível, após a insensibilização, para evitar o retorno à sensibilidade e minimizar defeitos na carne.

Tabela 4. Médias do intervalo entre atordoamento e sangria (segundos), tempo de sangria (minutos) e pH 24 horas, Uberlândia-MG, 2009.

\begin{tabular}{cccc}
\hline Lotes & $\begin{array}{c}\text { Intervalo entre atordoamento e } \\
\text { sangria (segundos) }\end{array}$ & Tempo de sangria (minutos) & pH 24horas \\
\hline 1 & $59,00^{\mathrm{a}}$ & $4,52^{\mathrm{a}}$ & $5,88^{\mathrm{b}}$ \\
2 & $56,10^{\mathrm{a}}$ & $4,38^{\mathrm{a}}$ & $5,85^{\mathrm{b}}$ \\
3 & $58,02^{\mathrm{a}}$ & $3,55^{\mathrm{b}}$ & $5,76^{\mathrm{c}}$ \\
4 & $54,07^{\mathrm{a}}$ & $4,21^{\mathrm{a}}$ & $5,83^{\mathrm{b}}$ \\
5 & $56,42^{\mathrm{a}}$ & $2,54^{\mathrm{c}}$ & $6,02^{\mathrm{a}}$ \\
6 & $51,70^{\mathrm{a}}$ & $4,47^{\mathrm{a}}$ & $5,84^{\mathrm{b}}$ \\
7 & $56,75^{\mathrm{a}}$ & $4,18^{\mathrm{a}}$ & $5,85^{\mathrm{b}}$ \\
8 & $58,95^{\mathrm{a}}$ & $3,38^{\mathrm{b}}$ & $5,90^{\mathrm{b}}$ \\
\hline
\end{tabular}

Médias com letras diferentes na mesma coluna diferem entre si de acordo com o teste de Tukey $(\mathrm{P}<0,05)$.

O tempo de sangria variou entre lotes $(\mathrm{P}<0,05)$, porém todos estavam dentro do tempo mínimo preconizado que é de 3 minutos, conforme Brasil (1997), exceto o lote 5 que apresentou menor tempo, como possível consequência de insensibilização inadequada (Tabela 4). Vimini et al. (1983) estabeleceram que o volume de sangue colhido é maior se a sangria for realizada imediatamente após a insensibilização e que este volume é inversamente proporcional ao intervalo entre o atordoamento e a sangria. Conforme Roça et al. (2001), para obtenção de uma carne com adequada capacidade de conservação, deve ser removido cerca de $60 \%$ do volume total de sangue na sangria, sendo que o restante fica retido nos músculos $(10 \%)$ e vísceras $(20-25 \%)$. O sangue tem $\mathrm{pH}$ alto $(7,35-7,45)$, grande teor proteico e tem uma rápida putrefação. Com isso, a capacidade de conservação da carne mal sangrada é limitada e constitui um problema de mau aspecto para o consumidor. Deste modo, a eficiência da sangria pode ser considerada uma importante operação de abate para a obtenção de um produto de qualidade. Um tempo menor de sangria retém mais sangue nos músculos e consequentemente interfere na conservação e pode alterar o pH final da carne, por estar sujeito a multiplicação bacteriana.

A média de $\mathrm{pH} 24$ horas post mortem do lote $3(5,76)$ foi considerada como ideal (Tabela 4). Entretanto, a maioria dos lotes obteve médias de $\mathrm{pH}$ 24 horas com valores intermediários (de 5,83 a $5,90)$. Os valores médios para as carcaças dos bovinos do lote 5 estavam acima de 6,0. Este resultado possivelmente ocorreu devido à falha no compressor que não enviou ar suficiente para a pistola pneumática. Devant et al. (2007) verificaram $13,89 \%$ das carcaças avaliadas com pH 5,80; 4,01\% com pH maior que 6,0 e $82,10 \%$ menor que 5,80 . Estes autores apontam o manejo na planta de abate como um dos fatores responsáveis pela elevação do $\mathrm{pH}$ da carne.

\section{CONCLUSÃO}

O manejo pré-abate no matadouro frigorífico influencia nos parâmetros de bem-estar animal, pois irregularidade de manutenção de equipamentos e instalações, mão de obra não qualificada e supervisão ineficiente provocam falhas nos processos de atordoamento, sangria e $\mathrm{pH} 24$ horas, com perda da qualidade da carne.

\footnotetext{
ABSTRACT: It was evaluated the pre-slaughter handling of 320 healthy and crossbred (zebu) cows, divided into eight groups of 40 animals, according to their origin, aged 2-4 years, coming from eight properties of Triângulo Mineiro - Minas Gerais, which were slaughtered in a slaughterhouse placed at the same region. It was related, in this handling, parameters of animal welfare and its effects on the stunning, bleeding and 24 hours pH. It was analyzed the leading of the animals in the slaughterhouse, from the pens until the stunning cabinet, the stunning of the cattle and the control of the time until the bleeding, the efficiency of the stunning and the measurement of $\mathrm{pH}$ of carcasses after 24 hours of slaughter. Considering each group of 40 animals, the slips and the falls varied from $0(0 \%)$ to 2 (5\%), and vocalizations from $0(0 \%)$ to $10(25 \%)$, numbered during the leading of the cattle. The smallest amount of the use of the electric stick per group of 40 animals was $23(57.5 \%)$ and the biggest one was $40(100 \%)$, which reflects the lack of an appropriate
} 
handling at this stage. The evaluated cattle, after stunning and properly numb, were among 31 to 40 animals (77.5\% to $100 \%)$ per group. The stunning with one shot ranged from 29 to 36 animals $(72.5 \%$ to $90 \%)$, except for one group, whose stunning was not efficient for defect in the equipment at the evaluation day and all the animals received more than one shot. The interval between stunning and bleeding did not vary $(\mathrm{P}>0.05)$ keeping within one minute. The bleeding time varied among groups $(\mathrm{P}<0.05)$, but within the recommended minimum time (3 minutes), except for one group that got less time (2.54 minutes). The averages amounts of 24 hours $\mathrm{pH}$ post mortem in one group kept in the recommended which is until 5,8; six groups kept among 5,81 a 5,99, considered intermediates in relation to the recommended pH. In one group, the average amounts to the carcasses of the cattle were more than 6,0; evaluated as undesired parameter, with marks the (5.81 to 5.99), one group had medium marks above 6.0. The pre-slaughter handling in the slaughterhouse influences the parameters of animal welfare, because irregular maintenance of equipment and facilities, unqualified workmanship and inefficient supervision cause failures in the processes of stunning, bleeding and 24 hours $\mathrm{pH}$, with loss of meat quality.

KEYWORDS: Cattle carcasses. Meat quality. pH. Slaughter. Stunning.

\section{REFERÊNCIAS}

ABIEC (Associação Brasileira das Indústrias Exportadores da Carne). Relatório detalhado sobre as exportações de carne brasileira, 2012. Disponível em: <http://www.abiec.com.br/estatisticas/100.pdf.>. Acesso em: 22 fev. 2013.

ANDRADE, E. N.; ROÇA, R. O.; SILVA, R. A. M.S. et al. Insensibilização de bovinos abatidos no Pantanal sul-mato-grossense e ocorrência de lesões em carcaças. Ciência Animal Brasileira, Goiânia, v. 9, n. 4, p. 958968, out./dez, 2008.

ALMEIDA, L. A. M. Manejo no pré-abate de bovinos: Aspectos Comportamentais e Perdas Econômicas por Contusões, 2005. Dissertação (Mestrado em Medicina Veterinária) - Faculdade de Ciências Agrárias e Veterinárias, Universidade Estadual Paulista "Júlio de Mesquita Filho". Jaboticabal, 2005.

BRASIL. Decreto no. 30691 de 29 de março de 1952 alterado pelo Decreto ${ }^{\circ}$. 2244 de quatro de junho de 1997. Aprova o Regulamento de Inspeção Industrial e Sanitária de Produtos de Origem Animal. Diário Oficial da União, Brasília, DF, 240p, 1997.

BRASIL. Ministério da Agricultura. Instrução Normativa no. 3, de 07 de janeiro de 2000. Regulamento técnico de métodos de insensibilização para o abate humanitário de animais de açougue. Diário Oficial da União, Brasília, p.14-16, 24 de janeiro de 2000. Disponível em: <http://www.agricultura.gov.br/das/dipoa/Anexo\%20Abate.htm>. Acesso em: 01 mar. 2013.

BRASIL. Ministério da Agricultura. Padronização de técnicas, instalações e equipamentos. Tomo I: Bovinos. DNPA. DIPOA, 183p, 1971. Disponível em:

<http://www.agricultura.gov.br/images/MAPA/arquivos_portal/manual_carnes,pdf> Acesso em: 01 mar. 2013.

BROOM, D. M.; MOLENTO, C. F. M. Bem-estar animal: conceito e questões relacionadas-revisão. Archives of Veterinary Science, Curitiba, v. 9, n. 2, p. 1-11, 2004.

COMISSÃO EUROPEIA. EU consumers willing to pay for better animal wefare, Bruxelas, 22 Março 2007. Disponível em: < http://europa.eu/rapid/pressReleasesAction.referen.HTML>. Acesso em: 28 fev. 2013.

DEVANT, M.; MACH, N.; BACH, A. et al. Association between animal, transportation, slaughterhouse practices, and meat pH in beef. Meat Science, Barking, v. 78, n. 3, p. 232-238, 2007.

FERREIRA, D. F. Análises estatísticas por meio do Sisvar para Windows versão 4.0. In: REUNIÃO ANUAL DA REGIÃO BRASILEIRA DA SOCIEDADE INTERNACIONAL DE BIOMETRIA, 45. UFSCar, São

Carlos, Anais... p. 255-258, 2006. 
GALLO, C.; GRANDIN, T.; TEUBER, C. et al. Mejoras en la insensibilización de bovinos con pistola neumática de proyectil retenido tras cambios de equipamiento y capacitación del personal. Archivos de Medicina Veterinaria, Valdívia, v. 35, n. 2, p. 159-170, 2003.

GALLO, C.; TADICH, N. Transporta terrestre de bovines: Efects sobre el Bienestar animal y la calidad de la carne. Agro-Ciência, Coquimbo, v. 21, n. 2, p. 37-49, 2005.

GRANDIN, T. Cattle slaughter audit form (updated october 2001) based on American Meat Institute Guidelines 2001. Disponível em: <http://www.grandin.com/cattle.audit.form.html >. Acesso em: 08 jan. 2013.

GRANDIN, T. Recommended Animal Handling Guidelines and Audit Guide for Cattle, Pigs, and Sheep. 2005 Edition, with 2007 Updates. Disponível em: <http://www.grandin.com/RecAnimalHandlingGuidelines.html>. Acesso em: 28 fev. 2013.

GRANDIN, T. The feasibility of using vocalization scoring as an indicator of poor welfare during cattle slaughter. Applied Animal Behaviour Science, Amsterdam, v. 56, n. 2-4, p. 121- 128. 1998.

http://dx.doi.org/10.1016/S0168-1591(97)00102-0

GRANDIN, T. Good management practices for animal handling and stunning. 2003. Disponível em: <http://aamp.com/documents/GMPsforAnimalHandling_000.pdf >. Acesso em: 03 dez. 2013.

GRANDIN, T. Using Prods and Persuaders Properly. 2009. Disponível em:

<http://www.grandin.com/behaviour/principles/prods.htm> Acesso em: 01 mar. 2013.

GREGORY, N., LEE, C.J., WIDDICOMBE, J.P. Depth of concussion in cattle shot by penetrating captive bolt. Meat Science, Barking, p. 499-503. 2007.

MITCHELL, L. Impact of Consumer Demand for Animal Welfare on Global Trade. 2006. Disponílvel em: http://www.ers.usda.gov/publications/wrs001/wrs011k.pdf Acesso em: 06 fev. 2013.

MOLENTO, C. F. M. Medicina Veterinária e bem-estar animal. Revista do Conselho Federal de Medicina Veterinária e Zootecnia, Brasília, v. 28/29, p. 15-20, 2003.

MOLENTO, C. F. M.; BOND, G. B. Produção e bem-estar animal - Aspectos éticos e técnicos da produção de bovinos. Ciência Veterinária dos Trópicos, Recife, v. 11, suplemento 1, p. 36-42, abril, 2008. Disponível em: <http://www.labea.ufpr.br/publicacoes/pdf/Recife\%20Bovinos.pdf >. Acesso em: 28 fev. 2013.

NEVES, J. E. G. Influências de métodos de abate no bem estar e na qualidade da carne de bovinos. 2008. 70f. Dissertação (Mestrado em Zootecnia) - Universidade Estadual Paulista "Julio de Mesquita Filho" Faculdade de Ciências Agrárias e Veterinárias Campus de Jaboticabal. Disponível em: $<$ http://www.fcav.unesp.br/download/pgtrabs/zoo/m/3486.pdf>. Acesso em: 08 jan. 2013.

PARANHOS DA COSTA, M. J. R. Ambiência e qualidade da carne. In: CONGRESSO DAS RAÇAS ZEBUÍNAS, 5., Anais... p. 170-174, L. A. Josahkian (Ed.): Uberaba-MG, 2002.

PARANHOS DA COSTA, M. J. R.; COSTA E SILVA, E. V.; CHIQUITELLI NETO, M.; ROSA, M. S. Contribuição dos estudos de comportamento de bovinos para implementação de programas de qualidade de carne. In: ENCONTRO ANUAL DE ETOLOGIA, 20., Anais... p. 71-89, Sociedade Brasileira de Etologia: Natal-RN, 2002.

PRATA, L. F.; FUKUDA, R. T. Fundamentos de Higiene e Inspeção de Carnes. V1, 326p, Jaboticabal, Funep: 2001.

ROÇA, R. O. Modificações post-mortem. Botucatu: FCA - UNESP, Botucatu, Artigo Técnico, 16p, 2000. 
ROÇA, R. O.; PADOVANI, C. R.; FILIPI, M. C.; SCHWACH, E.; UEMI, A.; SHINKAI, R. T.; BIOND, G. F. Efeitos dos métodos de abate de bovinos na eficiência da sangria. Ciência e Tecnologia de Alimentos, Campinas, v. 21, n. 2, p. 244-248, 2001. http://dx.doi.org/10.1590/S0101-20612001000200021

. Abate Humanitário de bovinos. In: CONFERÊNCIA VIRTUAL GLOBAL SOBRE PRODUÇÃO ORGÂNICA DE BOVINOS DE CORTE, 2002. Via Internet. Disponível em:

<http://www.cpap.embrapa.br/agencia/congressovirtual/pdf/portugues/02pt03.pdf/ >. Acesso em: 12 jan 2013.

VIMINI, R. J., FIELD, R. A., RILEY, M. L., et al Influence of delayed blending after stunning on beef muscle characteristics. Journal of Animal Science, Champaign, v. 56, n. 3, p. 608-615, 1983. 